Case Reports in
Gastroenterology
Case Rep Gastroenterol 2021;15:218-224

DOI: $10.1159 / 000511017$

Published online: February 18, 2021 (c) 2021 The Author(s)

Published by S. Karger AG, Base www.karger.com/crg

This article is licensed under the Creative Commons Attribution-NonCommercial 4.0 International License (CC BY-NC) (http://www.karger.com/Services/OpenAccessLicense). Usage and distribution for commercial purposes requires written permission.

\title{
Severe Hypertriglyceridemia-Induced Acute Pancreatitis
}

\author{
Gyula Molnár $^{\mathrm{a}} \quad$ V. Anna Gyarmathy ${ }^{\mathrm{b}, \mathrm{c}} \quad$ Noémi Zádorid ${ }^{\mathrm{d}}$ Péter Hegyi ${ }^{\mathrm{d}}$ e \\ Péter Kanizsai ${ }^{f, g}$

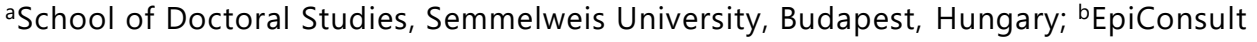 \\ Biomedical Consulting and Medical Communications Agency, Dover, DE, USA; ' Johns \\ Hopkins University, Baltimore, MD, USA; dInstitute for Translational Medicine, Medical

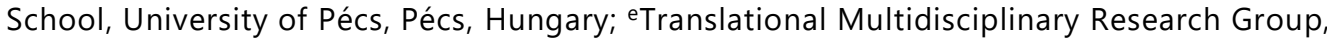 \\ Hungarian Academy of Sciences, University of Szeged, Szeged, Hungary; fUniversity \\ Department of Emergency Medicine, Clinical Centre, University of Pécs, Pécs, Hungary; \\ פSemmelweis University, Faculty of Medicine, Department of Anaesthesiology and \\ Intensive Care, Budapest, Hungary
}

\section{Keywords}

Familial hypercholesterolemia - Evolocumab - Alirocumab · Health economics and outcomes research · Pancreatitis
Abstract risk/benefit ratio.

The prevalence of familial hypercholesterolemia (FH) is about 1 in 200-500 in the general population, but approximately less than $1 \%$ of those affected are actually diagnosed. One of the most promising approaches to treat $\mathrm{FH}$ is utilizing human monoclonal antibodies. This is a case study describing a 47-year-old male patient who presented to the Emergency Department with acute abdominal pain caused by severe hypertriglyceridemia (HTG)-induced acute pancreatitis (AP). We report the steps necessary for establishing the right diagnosis and the management of HTG-induced AP, which are inevitable for the reduction of severity and mortality. This case study shows that hypercholesterolemia is an underdiagnosed and potentially lethal disease. Once diagnosed, all measures should be considered to control blood cholesterol and lipid levels. The decision to administer PCSK9 inhibitors should not be solely based on economical calculation, but rather individual factors should also be considered to weigh the 


\section{Case Reports in Gastroenterology}

\begin{tabular}{l|l}
\hline Case Rep Gastroenterol 2021;15:218-224 \\
\hline DOI: 10.1159/000511017 & $\begin{array}{l}\text { @ 2021 The Author(s). Published by S. Karger AG, Basel } \\
\text { www.karger.com/crg }\end{array}$ \\
\hline
\end{tabular}

Molnár et al.: Severe Hypertriglyceridemia-Induced Acute Pancreatitis

\section{Introduction}

Familial hypercholesterolemia (FH) is one of the most important underlying causes of coronary artery disease (CAD) worldwide, which has recently been showing an increasing trend [1]. FH is a genetically heterogeneous disorder, most often caused by mutations in the genes encoding the low-density lipoprotein receptor (LDLR) [2, 3]. Additionally, the mutations of some other genes (such as apoB, PCSK9, or ARH) might also cause FH, but such nonLDLR causes of FH are much rarer [4]. Genetic studies identified more than 2,500 different LDLR mutations in FH patients [4]. Most patients with FH are heterozygous, meaning they carry only a single dominant genetic mutation: heterozygous familial hypercholesterolemia (HeFH) affects about 1 in 200-500 people, although it might be more prevalent in certain populations [3].

In FH, the liver's regulated capacity to break down LDL cholesterol (LDL-C) is impaired [5]. The uncatabolized LDL molecules aggregate in cholesterol-laden foam cells, and the accumulation of these cells results in three main manifestations of FH: (1) high LDL-C; (2) cholesterol deposits in, for example, the skin of the eyelids, around the cornea, and in connective tissues of tendons; and (3) premature CAD [5]. Deposits in the arteries are dangerous because they can potentially lead to premature obliterative arterial diseases, such as CAD, ischemic stroke, and peripheral arterial obstruction. FH is associated with increased mortality, especially among young adults: the standardized mortality ratio in $\mathrm{HeFH}$ for all causes was estimated to be 183 for all ages and 902 between the ages of 20 and 39 years [6]. It is estimated that about $10 \%$ of acute coronary syndrome patients have $\mathrm{FH}$ [1].

Although a number of pharmacological treatment options exists for the treatment of $\mathrm{FH}$, one of the most promising approaches is utilizing human monoclonal antibodies, based on the following mechanism $[3,7]$. LDL binds with LDLR on the liver cell surface, and after LDL is transported into the endosomes and released to be broken down into cholesterol, LDLR migrates back to the cell surface to be recycled [1]. Proprotein convertase subtilisin/kexin 9 (PCSK9) forms a bond with LDLR and promotes its breakdown by preventing LDLR from migrating back to the cell surface [1]. Alirocumab (trade name Praluent) and evolocumab (trade name Repatha) are other human monoclonal antibodies approved for the second-line treatment of high cholesterol in adults.

Hypercholesterolemia is a potentially lethal disease. Given that it is a silent illness, numerous patients who suffer from it present to the healthcare system with severe conditions. We are describing below a case report of an FH patient who presented to the emergency department with no prior symptoms or diagnosis of FH.

\section{Case Presentation}

A 47-year-old male with known chronic obstructive pulmonary disorder presented to the emergency department with cramping and severe abdominal pain (visual analog scale: 10/10), which was aggravated by physical activity and breathing. He also had nausea and was vomiting. He had been experiencing these symptoms for a day. Upon clinical examination, his abdomen was distended and hard to palpate with epigastric tenderness. His blood pressure was $100 / 60 \mathrm{~mm} \mathrm{Hg}, \mathrm{SpO}_{2} 97$, pulse $150 / \mathrm{min}$, and body temperature $37.2^{\circ} \mathrm{C}$. His general status was moderate, and he was orientated and cooperative.

\section{Karger'=}




\section{Case Reports in Gastroenterology}

Case Rep Gastroenterol 2021;15:218-224

DOI: 10.1159/000511017

(c) 2021 The Author(s). Published by S. Karger AG, Basel www.karger.com/crg

Molnár et al.: Severe Hypertriglyceridemia-Induced Acute Pancreatitis

Laboratory investigations revealed a highly lipemic sample (Fig. 1) with serum triglyceride (TG) level of $7,520 \mathrm{mg} / \mathrm{dL}(84.9 \mathrm{mmol} / \mathrm{L})$ and total cholesterol of $870 \mathrm{mg} / \mathrm{dL}(22.5$ $\mathrm{mmol} / \mathrm{L}$ ). The leukocyte count was $11.4 \mathrm{G} / \mathrm{L}$, neutrophil ratio was $91.3 \%$, C-reactive protein $161.1 \mathrm{mg} / \mathrm{L}$, serum amylase levels $152 \mathrm{U} / \mathrm{L}$, and serum lipase $507 \mathrm{U} / \mathrm{L}$. Coagulation and biochemistry parameters could not be tested due to lipemic stimulation (lactescent serum; Fig. 1).

Abdominal ultrasound detected mild hepatomegaly with increased liver echogenicity and the pancreas could not be visualized because it was obscured by bowel gas. Abdominal X-ray was normal. Contrast-enhanced computer tomography (CT) scan of the abdomen was suggestive for acute pancreatitis (AP) with peripancreatic adipose tissue infiltration, necrosis of the pancreatic tail, and with modified CT severity index of 10 (Fig. 2).

The patient's Bedside Index of Severity in Acute Pancreatitis (BISAP) score was 1 at the initial evaluation. The patient was treated with severe HTG-induced AP (according to the revised Atlanta classification 2012) [7]. Due to the high mortality rate of HTG-induced AP, plasmapheresis was performed immediately. After 1 session of plasma exchange, his TG level decreased to $190.43 \mathrm{mg} / \mathrm{dL}(2.15 \mathrm{mmol} / \mathrm{L})$ and his cholesterol level to $212.7 \mathrm{mg} / \mathrm{dL}$ (5.5 $\mathrm{mmol} / \mathrm{L}$ ). Afterwards, enteral feeding, aggressive fluid resuscitation, and pain management were administered, which resulted in the improvement of the patient's condition. Statin, fibrate, and low-molecular weight heparin were administered as well. On day 6, the patient experienced severe dyspnea, and his inflammatory parameters in laboratory findings started to increase again. The X-ray revealed hydrothorax (HTX), and a large amount of fluid was visible on the left side. On the following day, the patient became febrile $\left(38^{\circ} \mathrm{C}\right)$; therefore, antibiotic therapy was initiated, but his clinical condition deteriorated regardless: his blood pressure became $114 / 74 \mathrm{~mm} \mathrm{Hg}$, his oxygen saturation decreased to $92 \%$, and his BISAP score increased to 3. Control abdominal CT scan showed necrotizing pancreatitis, HTX, and a progressed level of abdominal fluids (modified CTSI: 10). On day 8, the patient was referred to the Sub-Intensive Care Unit for further care. On day 11, due to his stable vital parameters and regression of the abdominal fluid collection, he was transferred back to the Department of Gastroenterology. In the following days, his general status improved: inflammatory parameters in the lab regressed, he became permanently afebrile, and control CT scans showed a significant regression of abdominal fluid collection and complete remission of HTX (modified CTSI: 6). After 29 days of hospitalization, the patient was discharged without symptoms and in good general condition, with fibrate and statin medication. However, PCSK9 inhibitor was not initiated in this case, but it is inevitable that in the event of unsuccessful statin and fibrate medication it should be implemented in the therapeutic regimen.

$\mathrm{AP}$ is one of the most important diseases that should be considered in the differential diagnosis in patients presenting to emergency departments with abdominal pain. AP can be induced by several different etiological factors. The third most common cause of AP is elevated TG levels. HTG leads to the most severe form of pancreatitis with a high mortality rate among all precipitating factors [8]. Though its exact pathogenesis remains unclear, it is known that the metabolites of TGs may induce direct and indirect cellular damages causing pancreatitis and, eventually, necrosis [9].

Unfortunately, there is no guideline available for managing HTG-induced AP. Rapid reduction of serum TG and its metabolites might be effective in preventing organ damages and should be taken into consideration [10]. Early diagnosis of these patients at the emergency department is crucially important since early management of HTG-induced AP is inevitable for the reduction of severity and mortality.

\section{Karger'=}




\section{Case Reports in Gastroenterology}

Case Rep Gastroenterol 2021;15:218-224

\begin{tabular}{l|l}
\hline DOI: 10.1159/000511017 & @ 2021 The Author(s). Published by S. Karger AG, Basel \\
\hline
\end{tabular} www.karger.com/crg

Molnár et al.: Severe Hypertriglyceridemia-Induced Acute Pancreatitis

\section{Discussion}

Given the genetic heterogeneity of FH, diagnosis based on routine molecular genetic testing is currently not feasible. Clinical diagnosis is, therefore, based mainly upon the assessment of previous medical history, biochemical markers, physical signs and associated symptoms, along with family history [5]. Although no study has assessed the extent of diagnosis, it is estimated that less than $1 \%$ of those affected are actually diagnosed [11]. Given that diseases associated with cardiovascular disease (CVD) - such as ischemic heart disease and stroke are leading causes of death, there is an urgent need to increase the number of patients that are diagnosed with FH [7].

HMG-CoA reductase inhibitors are the primary therapeutic interventions for hypercholesterolemia along with diet, but in some cases, such as statin intolerance and lack of effectivity with conventional therapy, other measures should be considered [12]. One of these is initiating therapy with PCSK9 inhibitors. In a systematic review, McDonagh et al. [12] found highstrength evidence from two 12-week randomized controlled trials that, compared with placebo administration, evolocumab 140 mg every 2 weeks to 420 mg every 4 weeks resulted in a greater LDL-C reduction in patients with $\mathrm{HeFH}$ initially on high-intensity statin plus ezetimibe, with a greater improvement in high-density lipoprotein cholesterol (HDL-C). In patients with homozygous FH on a maximum statin dose and ezetimibe, low-strength evidence suggested that evolocumab $420 \mathrm{mg}$ every 4 weeks reduced LDL-C significantly more than placebo. They found no difference in levels of HDL-C along with the percentage of patients with serious adverse events. In statin-intolerant patients, they found no evidence of the effectiveness of alirocumab.

With evolocumab $280 \mathrm{mg}$ every 4 weeks or $140 \mathrm{mg}$ every 2 weeks, a higher reduction of LDL-C was observed compared to placebo, with similar effects in HDL-C without any severe sequelae. In patients with high cardiovascular risk, secondary treatment with PCSK9 inhibitors was assessed. In high-risk patients, moderate-strength evidence showed that alirocumab resulted in a higher number of patients reaching the study goal in reduction of LDL-C at 24 weeks (relative risk 1.70, 95\% CI 1.46-1.95) than ezetimibe. Regarding overall adverse effects, moderate-strength evidence found no difference between alirocumab and ezetimibe with a high (69\%) rate of adverse event reporting. In terms of secondary treatment in patients with high cardiovascular risk, moderate-strength evidence found that alirocumab resulted in a higher proportion of patients with high cardiovascular risk reaching the study goals (relative risk $1.70,95 \%$ CI 1.46-1.95) than ezetimibe (10 mg). Moderate-strength evidence found that there was no difference in overall adverse event reporting between alirocumab and ezetimibe. In this patient population, moderate and low-level evidence found no difference in adjudicated cardiovascular events between alirocumab and ezetimibe at 52 weeks or between alirocumab and placebo at 52-78 weeks. In individuals receiving secondary treatment at varied cardiovascular risk, in short-term (12-weeks) comparisons of evolocumab and placebo, 2 studies on 996 patients with varying risk levels and not meeting LDL targets concluded that significantly more patients taking evolocumab compared with placebo and on statin therapy had a greater percentage of reduction in LDL-C. There is also moderate-strength evidence of modest HDL-C increases with evolocumab and moderate- to high-strength evidence of no differences in adverse events compared to placebo.

While alirocumab and evolocumab are effective medications, they are also very expensive. For example, Kazi et al. [13] concluded that, in the US, a reduction of annual drug prices from more than 14,000 USD to 4,536 USD would be necessary to meet a 100,000 USD per

\section{Karger'=}




\section{Case Reports in Gastroenterology}

\begin{tabular}{|c|c|}
\hline \multicolumn{2}{|c|}{ Case Rep Gastroenterol 2021;15:218-224 } \\
\hline DOI: $10.1159 / 000511017$ & $\begin{array}{l}\text { (c) } 2021 \text { The Author(s). Published by S. Karger AG, Basel } \\
\text { www.karger.com/crg }\end{array}$ \\
\hline
\end{tabular}

quality-adjusted life-years threshold for decreasing lifetime major adverse cardiovascular events. In Norway, Korman and Wisløff [14] found that PCSK9 inhibitors are cost-effective in the secondary prevention only for older patients with high absolute risk of CVD. This might change as the price of the substances begins to decrease. In a Spanish study, Olry de Labry Lima et al. [15] concluded that evolocumab was associated with a lower frequency of cardiovascular events, but the extra high costs of the medication made it cost-inefficient for patients suitable to receive this drug in the Spanish National Health System. Despite the inferred lack of cost-effectiveness, adding PCSK9 inhibitors to statin therapy is still recommended due to their protective effects on CVD. No study has assessed the cost-effectiveness of statin monotherapy versus evolocumab monotherapy, which remains to be evaluated, especially considering that since June 2019 the drug has been approved for use as a monotherapy for FH patients.

Hypercholesterolemia is an underdiagnosed and potentially lethal disease. Given that it is silent, numerous patients that suffer from it present to the healthcare system with severe conditions, such as the one depicted in our case report. Once diagnosed, all measures should be considered to control blood cholesterol and lipid levels. The decision to administer PCSK9 inhibitors should not be solely based on economical calculation, but rather individual factors should also be considered to weigh the risk/benefit ratio. The decision must stay with the physician treating patients with FH.

\section{Statement of Ethics}

The research was conducted ethically in accordance with the World Medical Association Declaration of Helsinki. The subject has given his written informed consent for publication including images.

The study protocol was approved by the relevant organization, the Scientific and Research Ethics Committee of the Hungarian Medical Research Council (17787-8/2020EÜIG).

\section{Conflict of Interest Statement}

The authors declare no conflict of interest.

\section{Funding Sources}

Semmelweis University.

\section{Author Contributions}

No writing assistance was provided in the preparation of the manuscript - it is entirely the work of the authors.

Gyula Molnár was involved in the study design, and wrote the paper. V. Anna Gyarmathy designed the study and wrote the paper. Noémi Zádori performed data collection and management, created the figures, and wrote the paper. Péter Hegyi contributed to writing the

\section{Karger'=}




\section{Case Reports in Gastroenterology}

Case Rep Gastroenterol 2021;15:218-224

DOI: $10.1159 / 000511017$

(c) 2021 The Author(s). Published by S. Karger AG, Basel www.karger.com/crg

Molnár et al.: Severe Hypertriglyceridemia-Induced Acute Pancreatitis

paper and to the creation of the figures. Péter L. Kanizsai provided recommendations for writing the paper and revised the manuscript. All authors provided final approval of the version submitted for publication.

\section{References}

1 Ogura M. PCSK9 inhibition in the management of familial hypercholesterolemia. J Cardiol. 2018 Jan;71(1):17.

2 Mytilinaiou M, Kyrou I, Khan M, Grammatopoulos DK, Randeva HS. Familial Hypercholesterolemia: New Horizons for Diagnosis and Effective Management. Front Pharmacol. 2018 Jul;9:707.

3 Hori M, Miyauchi E, Son C, Harada-Shiba M. Detection of the benign c.2579CT (p.A860V) variant of the LDLR gene in a pedigree-based genetic analysis of familial hypercholesterolemia. J Clin Lipidol. 2019 MarApr;13(2):335-9.

4 Yuan G, Wang J, Hegele RA. Heterozygous familial hypercholesterolemia: an underrecognized cause of early cardiovascular disease. CMAJ. 2006 Apr;174(8):1124-9.

5 Harada-Shiba M, Arai H, Ishigaki Y, Ishibashi S, Okamura T, Ogura M, et al.; Working Group by Japan Atherosclerosis Society for Making Guidance of Familial Hypercholesterolemia. Guidelines for Diagnosis and Treatment of Familial Hypercholesterolemia 2017. J Atheroscler Thromb. 2018 Aug;25(8):751-70.

6 Risk of fatal coronary heart disease in familial hypercholesterolaemia. Scientific Steering Committee on behalf of the Simon Broome Register Group. BMJ. 1991 Oct;303(6807):893-6.

7 Banks PA, Bollen TL, Dervenis C, Gooszen HG, Johnson CD, Sarr MG, et al.; Acute Pancreatitis Classification Working Group. Classification of acute pancreatitis - 2012: revision of the Atlanta classification and definitions by international consensus. Gut. 2013 Jan;62(1):102-11.

8 Baranyai T, Terzin V, Vajda Á, Wittmann T, Czakó LJ. Hypertriglyceridemia causes more severe course of acute pancreatitis. Clin Lipidol. 2012;7(6):731-6.

9 Havel RJ. Pathogenesis, differentiation and management of hypertriglyceridemia. Adv Intern Med. 1969;15:117-54

10 Zádori N, Gede N, Antal J, Szentesi A, Alizadeh H, Vincze Á, et al. EarLy Elimination of Fatty Acids iN hypertriglyceridemia-induced acuTe pancreatitis (ELEFANT trial): protocol of an open-label, multicenter, adaptive randomized clinical trial. Pancreatology. 2020 Apr;20(3):369-376.

11 Nordestgaard BG, Chapman MJ, Humphries SE, Ginsberg HN, Masana L, Descamps OS, et al.; European Atherosclerosis Society Consensus Panel. Familial hypercholesterolaemia is underdiagnosed and undertreated in the general population: guidance for clinicians to prevent coronary heart disease: consensus statement of the European Atherosclerosis Society. Eur Heart J. 2013 Dec;34(45):3478-90a.

12 McDonagh M, Peterson K, Holzhammer B, Fazio S. A Systematic Review of PCSK9 Inhibitors Alirocumab and Evolocumab. J Manag Care Spec Pharm. 2016 Jun;22(6):641-653q.

13 Kazi DS, Moran AE, Coxson PG, Penko J, Ollendorf DA, Pearson SD, et al. Cost-effectiveness of PCSK9 Inhibitor Therapy in Patients with Heterozygous Familial Hypercholesterolemia or Atherosclerotic Cardiovascular Disease. JAMA. 2016 Aug;316(7):743-53.

14 Korman M, Wisløff T. Modelling the cost-effectiveness of PCSK9 inhibitors vs. ezetimibe through LDL-C reductions in a Norwegian setting. Eur Heart J Cardiovasc Pharmacother. 2018 Jan;4(1):15-22.

15 Olry de Labry Lima A, Gimeno Ballester V, Sierra Sánchez JF, Matas Hoces A, González-Outón J, Alegre Del Rey EJ. Cost-effectiveness and Budget Impact of Treatment with Evolocumab Versus Statins and Ezetimibe for Hypercholesterolemia in Spain. Rev Esp Cardiol (Engl Ed). 2018 Dec;71(12):1027-35. 
Case Reports in Gastroenterology
Case Rep Gastroenterol 2021;15:218-224

DOI: $10.1159 / 000511017$

(c) 2021 The Author(s). Published by S. Karger AG, Basel www.karger.com/crg

Molnár et al.: Severe Hypertriglyceridemia-Induced Acute Pancreatitis

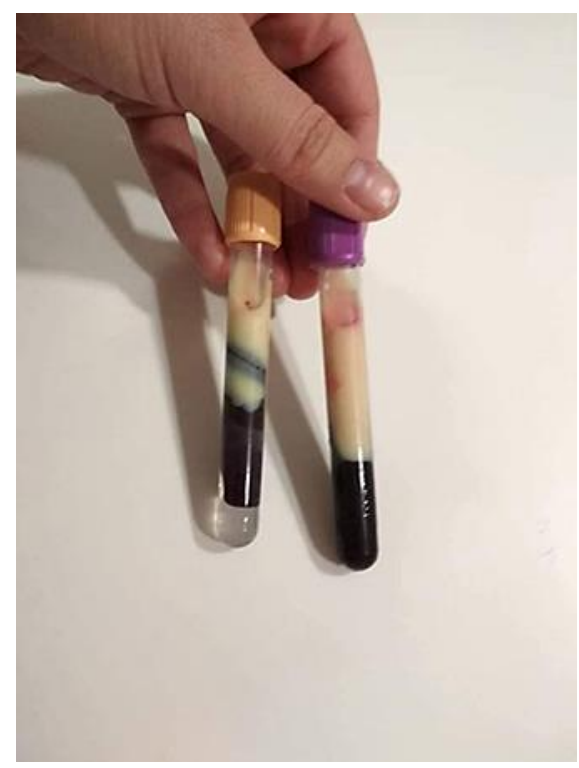

Fig. 1. Blood sample of the patient.

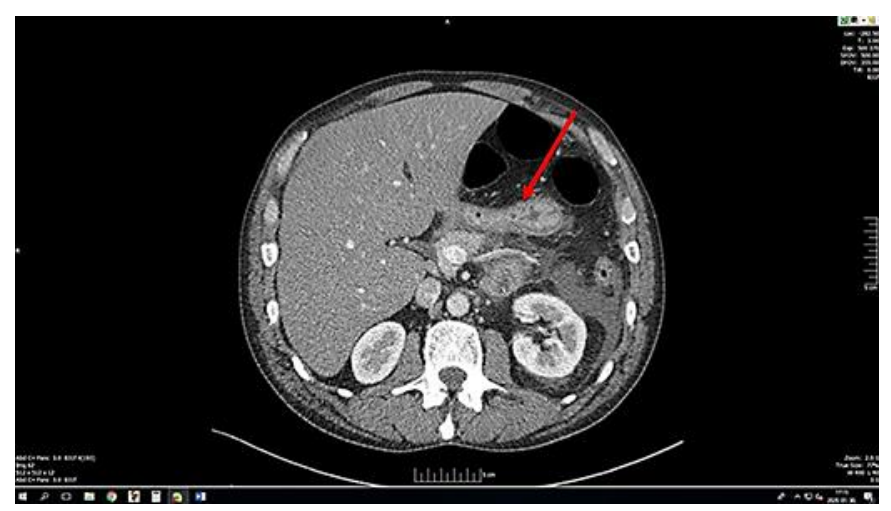

Fig. 2. CT scan of the patient's abdomen (patient identifiers removed). 